\title{
Comparison of culture media for detecting methicillin resistance in Staphylococcus aureus and coagulase negative staphylococci
}

\author{
LORNA M MILNE, G D W CURTIS, M CROW, WILMA A G KRAAK, J B SELKON \\ From the Public Health Laboratory, John Radcliffe Hospital, Oxford
}

SUMMARY The detection of methicillin resistance was examined in 51 strains of Staphylococcus aureus and 135 strains of coagulase negative staphylococci using Isosensitest, Diagnostic Sensitivity Test (DST), Mueller-Hinton (MH), Columbia, and Sensitest agars. MH agar with 5\% added sodium chloride incubated at $35^{\circ} \mathrm{C}$ was the most effective in detecting resistance in $S$ aureus, and Columbia agar with $5 \%$ added sodium chloride incubated at $35^{\circ} \mathrm{C}$ was most effective for coagulase negative staphylococci. For clinical purposes, a provisional report of sensitivity for $S$ aureus could be issued after 18 hours; with coagulase negative staphylococci, only resistant strains could be reported at this time. For definitive results cultures must be examined after $\mathbf{4 0}$ hours of incubation.

Resistance to methicillin in Staphylococcus aureus is usually heterogeneous and due to the presence of a component which sometimes only manifests resistance if grown on osmotically supportive media ${ }^{1}$ or if cultured at $30^{\circ} \mathrm{C}^{2}$ for up to 48 hours. ${ }^{3}$ Snell et al ${ }^{4}$ recommended that incubation at $30^{\circ} \mathrm{C}$ or adding $5 \%$ sodium chloride to the medium, or both, be used for methicillin testing. Despite the heterogeneous nature of the resistance in $S$ aureus to methicillin it has been shown to be clinically relevant in that it impairs the response to treatment with methicillin. ${ }^{5}$ Resistance to methicillin in coagulase negative staphylococci has also been shown to be due to heterogeneous populations and to be enhanced by growth on hypertonic medium or incubation at $30^{\circ} \mathrm{C}$ or for 48 hours. $^{6}$

In addition to these factors, the detection of methicillin resistance can be affected by the basal test medium used. Hindler and Inderleid ${ }^{7}$ showed that when $\mathrm{MH}$, an undefined medium, was used from five different manufacturers there were differences in the detection of resistance of $S$ aureus to methicillin.

Brown and Kothari $^{8}$ determined the minimum inhibitory concentration (MIC) of strains of $S$ aureus using MH, DST, Sensitest, and Wellcotest agars, and all gave similar results when incubated at $30^{\circ} \mathrm{C}$ for 18 hours. In view of the increasing clinical importance of

Accepted for publication 29 April 1987 coagulase negative staphylococci we examined several media to determine the optimal test conditions for detecting the methicillin resistance of both $S$ aureus and coagulase negative staphylococci.

\section{Material and methods}

The 186 strains of staphylococci tested consisted of eight reference strains from national collections, three strains from quality control schemes, and 175 clinical isolates. Many of the clinical isolates were selected because of difficulty in the interpretation of the disc sensitivity test.

Columbia (CM331), Diagnostic Sensitivity Test (DST) (CM261), Isosensitest (CM471), MuellerHinton (MH) (CM337), and Sensitest (CM409) agars were obtained from Oxoid Limited. The media were prepared according to the manufacturer's instructions, except that initial suspension of the powder was made in nine tenths of the recommended volume of water. After sterilisation and cooling to $45^{\circ} \mathrm{C}$ the remaining one tenth volume was made up by the addition of appropriate sterile aqueous solutions of methicillin (Sigma Chemical Company) to give final concentrations of $0,0.5,1,2,4,8$ and $16 \mu \mathrm{g} / \mathrm{ml}$. A duplicate set of media containing an additional $50 \mathrm{~g} / 1$ sodium chloride was prepared at the same time. The poured plates were refrigerated overnight before inoculation the next day.

All strains were examined by the method of Harvey 
and Gilmour. ${ }^{9}$ Seventeen strains, which failed to provide good identification, were further tested using the API STAPH system (API Laboratory Products Limited).

The MIC tests were performed according to the National Committee for Clinical Laboratory Standards (NCCLS) Tentative Standard M7-T (1983), using a multipoint inoculating device. Plates containing added sodium chloride were incubated at $35^{\circ} \mathrm{C}$, and those without sodium chloride at $30^{\circ} \mathrm{C}$. Readings were made at 18 hours and 40 hours, the MIC being recorded as the lowest concentration of antimicrobial agent that completely inhibited growth. A single colony or a faint haze caused by the inoculum was disregarded. Strains were considered to be resistant to methicillin if their MIC was $\geqslant 8 \mu \mathrm{g} / \mathrm{ml}$ on two separate tests and sensitive if their MIC was $<8 \mu \mathrm{g} / \mathrm{ml}$. The MIC test was repeated on any strain producing a result that could not be interpreted by NCCLS criteria-that is, gave an unclear end point or insufficient growth on the control medium without added antibiotic.

The eight reference strains and three quality control strains were tested and designated as sensitive or resistant by Dr RC George, Division of Hospital Infection, Central Public Health Laboratory, Colindale.

\section{Results}

Table 1 shows that all 51 strains of $S$ aureus grew satisfactorily on each medium by 18 hours. Twenty strains were sensitive under all test conditions. Of the remaining 31 strains, 28 showed resistance on more than one medium. The other three strains were resistant (MIC $=8 \mu \mathrm{g} / \mathrm{ml}$ ) only on MH agar with $5 \%$ added sodium chloride after $\mathbf{4 0}$ hours of incubation.

Sensitest and Isosensitest media performed considerably worse than the others-notably after 18 hours. All media detected more strains as resistant after $\mathbf{4 0}$ hours than at 18 hours. After 40 hours MH with 5\% added sodium chloride detected $31(100 \%)$ of the 31 resistant strains and Columbia and DST with 5\% added sodium chloride detected $26(84 \%)$. After 40 hours the performance of MH, DST, and Columbia incubated at $30^{\circ} \mathrm{C}$ were similar in that they detected $87 \%, 90 \%$, and $81 \%$, respectively, of the resistant strains.

Table 2 shows the results obtained with 135 strains of coagulase negative staphylococci. At 18 hours 25 strains failed to show adequate growth on one or more media. At 40 hours six strains failed to grow adequately on some of the media, but all grew on Columbia with or without added sodium chloride. Seventy two strains were designated as sensitive on all media after $\mathbf{4 0}$ hours' incubation. Forty eight strains showed resistance on at least one medium after 18 hours incubation and 63 after $\mathbf{4 0}$ hours. Again, Sensitest and Isosensitest media performed inadequately. After $\mathbf{4 0}$ hours of incubation the use of $5 \%$ sodium chloride in the Columbia and DST media was shown to be advantageous. Columbia with $5 \%$ added sodium chloride detected $55(87 \%)$ of the 63 resistant strains and DST with $5 \%$ added sodium chloride, 47 $(75 \%)$.

In contrast to the results with $S$ aureus, $\mathrm{MH}$ with $5 \%$ added sodium chloride detected only $35(56 \%)$ of the resistant strains. The media without additional sodium chloride detected a lower percentage of resistant strains at 40 hours, Columbia agar $73 \%$, MH $54 \%$, and DST $44 \%$. Eight resistant strains were not detected using Columbia with $5 \%$ added sodium chloride at $35^{\circ} \mathrm{C}$. Six of these were detected using Columbia agar at $30^{\circ} \mathrm{C}$. $\mathrm{MH}$ at $30^{\circ} \mathrm{C}$ detected four of these eight strains and $\mathrm{MH}$ with $5 \%$ added sodium chloride, one. DST at $30^{\circ} \mathrm{C}$ detected three, and DST with $5 \%$ added sodium chloride, none.

Table 3 shows more detailed results of the 11 reference and quality control strains. None of the media showed a sensitive strain as resistant. Resistant strains, however, were found to be sensitive under

Table 1 MICs of methicillin for 51 strains of Staphylococcus aureus recorded after 18 hours and 40 hours of incubation

\begin{tabular}{|c|c|c|c|c|c|c|}
\hline & \multicolumn{3}{|c|}{18 hours } & \multicolumn{3}{|c|}{40 hours } \\
\hline & $\geqslant 8$ & $<8$ & $N G / I S G$ & $\geqslant 8$ & $<8$ & $N G / I S G$ \\
\hline Col $+\underset{\text { Col }}{5 \%}$ sodium chloride & $\begin{array}{l}24 \\
24\end{array}$ & $\begin{array}{l}27 \\
27\end{array}$ & $\begin{array}{l}\mathbf{0} \\
\mathbf{0}\end{array}$ & $\begin{array}{l}26 \\
25\end{array}$ & $\begin{array}{l}25 \\
26\end{array}$ & $\begin{array}{l}\mathbf{0} \\
\mathbf{0}\end{array}$ \\
\hline DST $+\underset{\text { DST }}{5 \%}$ sodium chloride & $\begin{array}{l}22 \\
20\end{array}$ & $\begin{array}{l}29 \\
31\end{array}$ & $\begin{array}{l}\mathbf{0} \\
\mathbf{0}\end{array}$ & $\begin{array}{l}26 \\
28\end{array}$ & $\begin{array}{l}25 \\
23\end{array}$ & $\begin{array}{l}0 \\
0\end{array}$ \\
\hline $\mathrm{MH}+\underset{\mathrm{MH}}{5 \%}$ sodium chloride & $\begin{array}{l}24 \\
27\end{array}$ & $\begin{array}{l}27 \\
24\end{array}$ & $\begin{array}{l}0 \\
0\end{array}$ & $\begin{array}{l}31 \\
27\end{array}$ & $\begin{array}{l}20 \\
24\end{array}$ & $\begin{array}{l}0 \\
0\end{array}$ \\
\hline Sens $+\underset{\text { Sens }}{5 \%}$ sodium chloride & 13 & $\begin{array}{l}50 \\
38\end{array}$ & $\begin{array}{l}0 \\
0\end{array}$ & $\begin{array}{l}13 \\
21\end{array}$ & $\begin{array}{l}38 \\
30\end{array}$ & $\begin{array}{l}0 \\
0\end{array}$ \\
\hline $\begin{array}{c}\text { Iso }+5 \% \text { sodium chloride } \\
\text { Iso }\end{array}$ & $\begin{array}{l}0 \\
9\end{array}$ & $\begin{array}{l}51 \\
42\end{array}$ & $\begin{array}{l}\mathbf{0} \\
\mathbf{0}\end{array}$ & $\begin{array}{l}17 \\
19\end{array}$ & $\begin{array}{l}34 \\
32\end{array}$ & $\begin{array}{l}0 \\
0\end{array}$ \\
\hline
\end{tabular}

Abbreviations: Col = Columbia agar, DST = Diagnostic sensitivity agar, $\mathbf{M H}=$ Mueller-Hinton agar, Sens = Sensitest agar, Iso = Isosensitest agar, NG = No growth, ISG = Insufficient growth 
Table 2 MICs for methicillin for 135 strains of coagulase negative staphylococci* recorded after 18 hours and 40 hours of incubation

\begin{tabular}{|c|c|c|c|c|c|c|}
\hline & \multicolumn{3}{|c|}{18 hours } & \multicolumn{3}{|c|}{40 hours } \\
\hline & $\geqslant 8$ & $<8$ & $N G / I S G$ & $\geqslant 8$ & $<8$ & $N G / I S G$ \\
\hline Col $+\underset{\text { Col }}{5 \%}$ sodium chloride & $\begin{array}{l}36 \\
32\end{array}$ & $\begin{array}{r}97 \\
100\end{array}$ & $\begin{array}{l}2 \\
3\end{array}$ & $\begin{array}{l}55 \\
46\end{array}$ & $\begin{array}{l}80 \\
89\end{array}$ & $\begin{array}{l}0 \\
0\end{array}$ \\
\hline DST $+\underset{\text { DST }}{5 \%}$ sodium chloride & $\begin{array}{l}25 \\
23\end{array}$ & $\begin{array}{l}109 \\
108\end{array}$ & $\begin{array}{l}1 \\
4\end{array}$ & $\begin{array}{l}47 \\
28\end{array}$ & $\begin{array}{r}87 \\
106\end{array}$ & 1 \\
\hline $\begin{array}{c}\mathrm{MH}+\underset{\mathrm{MH}}{5 \%} \text { sodium chloride } \\
\end{array}$ & $\begin{array}{l}20 \\
21\end{array}$ & $\begin{array}{l}109 \\
103\end{array}$ & $\begin{array}{r}6 \\
11\end{array}$ & $\begin{array}{l}35 \\
34\end{array}$ & $\begin{array}{r}98 \\
100\end{array}$ & $\begin{array}{l}2 \\
1\end{array}$ \\
\hline Sens $+\underset{\text { Sens }}{5 \%}$ sodium chloride & $\begin{array}{r}3 \\
14\end{array}$ & $\begin{array}{l}120 \\
110\end{array}$ & 12 & $\begin{array}{l}11 \\
18\end{array}$ & $\begin{array}{l}121 \\
115\end{array}$ & $\begin{array}{l}3 \\
2\end{array}$ \\
\hline $\begin{array}{l}\text { Iso }+5 \% \text { sodium chloride } \\
\text { Iso }\end{array}$ & $\begin{array}{r}1 \\
10\end{array}$ & $\begin{array}{l}126 \\
112\end{array}$ & $\begin{array}{r}8 \\
13\end{array}$ & $\begin{array}{r}7 \\
19\end{array}$ & $\begin{array}{l}124 \\
115\end{array}$ & $\begin{array}{l}4 \\
1\end{array}$ \\
\hline
\end{tabular}

Abbreviations: Col = Columbia agar, DST = Diagnostic sensitivity agar, MH = Mueller-Hinton agar, Sens = Sensitest agar, Iso $=$ Isosensitest agar, $\mathbf{N G}=$ No growth, ISG $=$ Insufficient growth

* Staphylococcus epidermidis $93, S$ haemolyticus $19, S$ simulans $11, S$ warneri $6, S$ capitis $3, S$ xylosus $2, S$ hominis 1

several test conditions, especially after 18 hours-for example, strain 12 was sensitive on DST with $5 \%$ added sodium chloride after 18 hours, but resistant at 40 hours. Isosensitest and Sensitest agars, with or without $5 \%$ added sodium chloride were unreliable and yielded erroneous results with nine of these 11 strains. Columbia and $\mathrm{MH}$ agars with or without $5 \%$ added sodium chloride were the most reliable media and when incubated for $\mathbf{4 0}$ hours detected all the resistant strains.

\section{Discussion}

Any method of antibiotic sensitivity testing adopted by a clinical laboratory must produce a reliable result as early as possible. There have been many attempts to define how best to test for methicillin resistance, ${ }^{1-3}$ and the large number of reports clearly reflects the difficult nature of the problem. The recent reemergence of epidemic strains of methicillin resistant
$S$ aureus $^{10}$ and of methicillin resistant coagulase negative staphylococci in prosthetic heart valves, orthopaedic implants, and cerebrospinal fluid shunts has highlighted the need for a reliable method of laboratory testing. Previous studies of media have dealt only with $S$ aureus $^{78}$ or have examined both coagulase positive and negative species as a single group. ${ }^{11}$ It is clear from tables 1 and 2 that these two groups behave differently in methicillin sensitivity tests and must be considered separately.

All strains of $S$ aureus grew on each medium exam ined by 18 hours. After 18 hours of incubation Coos umbia and MH agars, whether or not $5 \%$ sodiun chloride was included, performed better than the other media because they detected more of the resistant isolates. After $\mathbf{4 0}$ hours' incubation $\mathrm{MH}$ with $5 \%$ added sodium chloride was the best medium for detecting all resistant strains. We therefore recommend MH agar with $5 \%$ added sodium chloride when using the breakpoint method for the detection of

Table 3 Results of quality control and reference strains

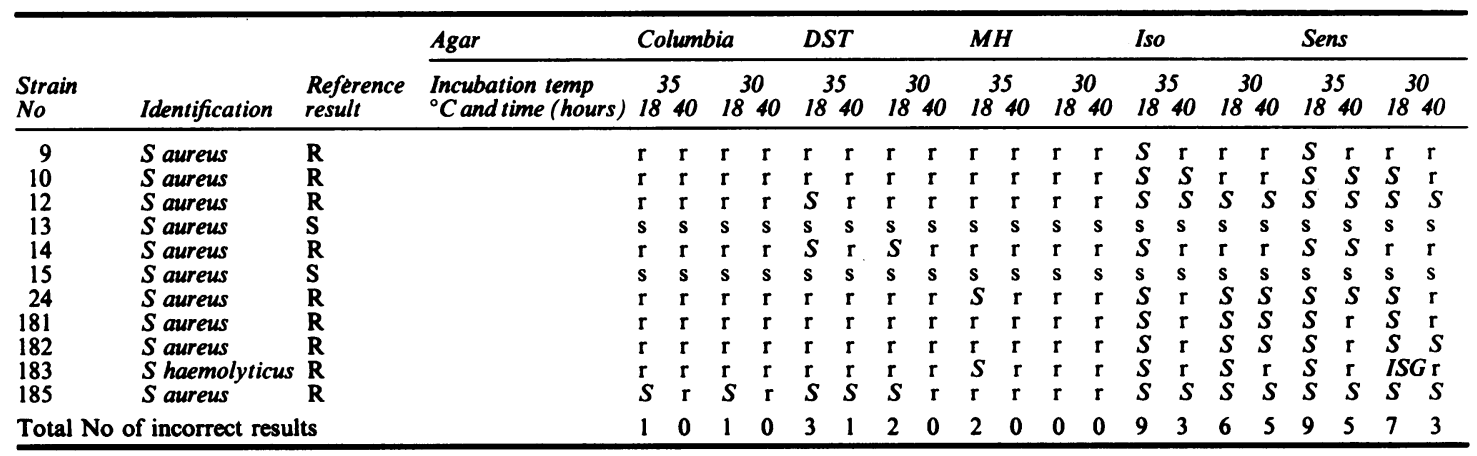

Media incubated at $35^{\circ} \mathrm{C}$ contained $5 \%$ sodium chloride

$\mathrm{r}=$ resistant strain (MIC $\geqslant 8 \mu \mathrm{g} / \mathrm{ml}$ ) determined as resistant, $\mathrm{s}=$ sensitive strain (MIC $<8 \mu \mathrm{g} / \mathrm{ml}$ ) determined as sensitive, $S=$ resistant strain determined as sensitive, ISG $=$ insufficient growth. 
resistance to methicillin in $S$ aureus. A reading at 18 hours would detect nearly all the resistant strains and a provisional report could be issued at that time. In only a few strains would this have to be changed after 40 hours.

The greatest difference between the media was evident with coagulase negative staphylococci. The use of a more nutritious agar than the semidefined media specially formulated for sensitivity testing is advisable, and only Columbia agar supported the growth of all strains after $\mathbf{4 0}$ hours of incubation. $\mathrm{MH}$ agar with or without added sodium chloride was not satisfactory for detecting methicillin resistance in coagulase negative staphylococci. The medium of choice for coagulase negative staphylococci is Columbia agar with $5 \%$ added sodium chloride incubated at $35^{\circ} \mathrm{C}$. After 18 hours of incubation only resistant coagulase negative staphylococci should be reported and the remaining strains incubated until $\mathbf{4 0}$ hours incubation has been completed.

In conclusion, none of the five media with or without added $5 \%$ sodium chloride, and irrespective of incubation temperature, provided complete detection of methicillin resistance in both $S$ aureus and coagulase negative staphylococci. For $S$ aureus we recommend MH agar with 5\% added sodium chloride and for coagulase negative staphylococci, Columbia agar with $5 \%$ added sodium chloride, both incubated at $35^{\circ} \mathrm{C}$ for 40 hours.

\section{References}

1 Barber M. Naturally occurring methicillin-resistant staphylococci. J Gen Microbiol 1964;35:183-90.
2 Annear DT. The effect of temperature on resistance of Staphylococcus aureus to methicillin and some other antibiotics. Med $J$ Aust 1968;1:444-6.

3 Hewitt JH, Coe AW, Parker MT. The detection of methicillin resistance in Staphylococcus aureus. $J$ Med Microbiol 1969;2:443-55.

4 Snell JJS, Brown DFJ, Gardner PS. Comparison of results from two antibiotic susceptibility testing trials that formed part of the United Kingdom national external quality assessment scheme. J Clin Pathol 1984;37:321-8.

5 Chabbert YA, Baudens JG, Acar JF, Gerbaud GR. La resistance naturelle des staphylocoques à la methicillin et l'oxacilline. Revue Française d'Etudes Cliniques et Biologiques 1965;10:495-506.

6 Archer GL. Antimicrobial susceptibility and selection of resistance among Staphylococcus epidermidis isolates recovered from patients with infection of indwelling foreign devices. Antimicrob Agents Chemother 1978;14:353-9.

7 Hindler JA, Inderleid CB. Effect of the source of Mueller-Hinton agar and resistance frequency on the detection of methicillinresistant Staphylococcus aureus. J Clin Microbiol 1985;21:205-10.

8 Brown DFJ, Kothari D. The reliability of methicillin sensitivity tests on four culture media. J Clin Pathol 1974;27:420-6.

9 Harvey J, Gilmour A. Application of current methods for isolation and identification of staphylococci in raw bovine milk. $J$ Appl Bacteriol 1985;59:207-21.

10 Marples RR, Richardson JF, deSaxe MJ. Bacteriological characteristics of strains of Staphylococcus aureus submitted to a reference laboratory related to methicillin resistance. $J \mathbf{H y g}$ 1986;96:217-24.

11 McDougall LK, Thornsberry C. New recommendations for disc diffusion antimicrobial susceptibility tests for methicillinresistance (heteroresistant) staphylococci. J Clin Microbiol 1984;19:482-8.

Requests for reprints to Dr Lorna M Milne, Public Health Laboratory, Level 6/7, John Radcliffe Hospital, Headington, Oxford, England. 